\title{
Towards an Ontology for Strategic Decision Making: The Case of Quality in Rapid Software Development Projects
}

\author{
Cristina Gómez ${ }^{1}$, Claudia Ayala ${ }^{1}$, Xavier Franch ${ }^{1}$, Lidia López ${ }^{1}$, Woubshet Behutiye ${ }^{2}$, \\ Silverio Martínez-Fernández ${ }^{3}$ \\ ${ }^{1}$ Universitat Politècnica de Catalunya (UPC), Barcelona, Spain \\ \{cristina, cayala, llopez, franch\}@essi.upc.edu \\ ${ }^{2}$ University of Oulu, Oulu, Finland \\ Woubshet.Behutiye@oulu.fi \\ ${ }^{3}$ Fraunhofer IESE, Kaiserslautern, Germany \\ Silverio.Martinez@iese.fraunhofer.de
}

\begin{abstract}
Strategic decision making is the process of selecting a logical and informed choice from the alternative options based on key strategic indicators determining the success of a specific organization strategy. To support this process and provide a common underlying language, in this work, we present an empirically-grounded ontology to support different strategic decision-making processes and extend the ontology to cover the context of managing quality in Rapid Software Development projects. We illustrate the complete ontology with an example.
\end{abstract}

Keywords: Rapid software development, Strategic decision-making, Ontology.

\section{$1 \quad$ Introduction}

Decision making is the process of selecting a logical and informed choice from the available options. When the logical choice is based on key factors determining the success of a specific organization-oriented strategy, this process is called strategic decision making. Strategic decisions are important because without them actions will not be planned to follow organizations' strategies.

Nowadays, techniques for decision making are applied to several fields such as business management and software engineering among others. In addition to these techniques, there are tools to help decision makers in the process of making decisions. Examples of these tools are decision support systems to cope with decision-making activities, and strategic dashboards to provide a view of strategic indicators.

A way of providing a common underlying language integrating the concepts to manage decisions and to handle strategic indicators is to define an ontology. This ontology enables structuring the knowledge in a way that favors its understanding and communication and, consequently, it could be used as a basis for the construction of tools supporting strategic decision making. Moreover, this ontology will be used, in future versions, to provide reasoning capabilities such as suggestions on demand.

adfa, p. 1, 2011

(C) Springer-Verlag Berlin Heidelberg 2011 
The goal of this paper is twofold: 1) to present a preliminary Strategic DecisionMaking (SDM) ontology to support different strategic decision-making processes and 2) to extend the SDM ontology to cover the context of managing quality in Rapid Software Development (RSD) projects.

The SDM ontology identifies the key terms through a glossary and their relationships through a conceptual model, represented with a UML class diagram and associated integrity constraints. We illustrate the possible use of the SDM ontology for assuring quality in RSD within the context of the research and innovation European H2020 project Q-Rapids ${ }^{1}$ and provide an example for this context.

The rest of the paper is structured as follows. Section 2 discusses the related work in the area and Section 3 explains the research approach followed to define the SDM ontology. Section 4 elaborates the generic SDM ontology. Section 5 extends the SDM ontology to cover the context of the Q-Rapids project and presents an example. Finally, Section 6 summarizes the conclusions and identifies future work.

\section{Related Work}

We reviewed the extensive literature on how to model and measure the strategy of an organization. Basically, we are interested in identifying the concepts of strategic decision making, which are relevant for decision makers, and mapping those concepts to the context of quality requirements in RSD. We used these concepts to model and measure strategic indicators for supporting decision making.

The Balance Scorecard (BSC), proposed by Kaplan et al. [1], is a business framework used for describing and measuring an organization's strategy and for tracking the actions taken to improve the results. In this sense, the BSC proposes to define strategic objectives and key performance indicators (KPIs) to measure those strategic objectives and actions that the organization should take into account to achieve the objectives. The BSC has been applied in the context of measuring software quality ${ }^{2}$.

The Business Motivation Metamodel (BMM) [2] provides concepts for developing, communicating and managing business plans in an organized manner. Specifically, the BMM defines concepts such as strategy and goals. In the same sense, the Business Intelligence $\mathrm{Model}^{3}$ (BIM) [3] provides constructs for modelling business organizations at strategic level. In particular, concepts such as actors and KPIs are defined.

$\mathrm{KPI}$, as a way of monitoring, is a crucial concept that has received a lot of attention in the literature. There exist catalogues of KPIs to measure several aspects of an organization. For instance, the Scoro work management software solution ${ }^{4}$ provides 16 essential project KPIs to track a project's performance (e.g., return on investment, overdue project tasks/crossed deadlines). Enfocus Solutions ${ }^{5}$ defines KPIs for business analysis and project management (e.g., project stakeholder satisfaction index,

\footnotetext{
${ }^{1}$ Q-Rapids' website: http://q-rapids.eu/

${ }^{2} \mathrm{http} / / / \mathrm{www} \cdot \mathrm{bscdesigner} . c o m / \mathrm{bsc}-$ for-software-quality-guide.htm

${ }^{3} \mathrm{http}: / / \mathrm{www} . \mathrm{cs}$.toronto.edu/ jm/bim/

${ }^{4} \mathrm{https}: / / \mathrm{www}$.scoro.com/blog/16-essential-project-kpis/

${ }^{5} \mathrm{http}$ ://enfocussolutions.com/kpis-for-business-analysis-and-project-management/
} 
and number of milestones missed). Besides, $\mathrm{CBS}^{6}$ (Center for Business Practices) enumerates a comprehensive list of measures of project management and value in the context of IT organizations (e.g., average time to repair a defect, alignment to strategic business goals). An ontology in which KPIs are described together with their mathematics formulas is explained in [4].

In [5], Maté et al. present a semi-automatic approach that performs a partial search guided by the KPIs of the company, generating queries required during the monitoring process to discover the existence of problems and where they are located. Another approach that provides decision makers with an integrated view of strategic business objectives linked to conceptual data warehouses KPIs is presented in [6].

Regarding the decision-making process, the Decision Model and Notation (DMN) metamodel [7] provides the constructs that are needed to model decisions. DMN defines concepts such as decision, decision maker and knowledge requirement.

Previous works provide meta-models, ontologies and constructs representing concepts as KPIs, decision, and actions among others. However, there is not an integrated ontology establishing relationships among those concepts, which is our purpose.

\section{Research Approach}

This work was carried out under the context of the Q-Rapids European project [8] that aims to improve the management of quality requirements in RSD processes. To achieve this goal, the project aims to promote a highly informative dashboard to support making strategic decisions in rapid cycles. Such a dashboard will be based on the extraction and analysis of information to systematically and continuously assess software quality using a set of quality-related indicators based on GQM+Strategies ${ }^{\mathrm{TM}}$ [9] in order to support decision-making processes. Information will be extracted from diverse repositories containing information about the software development process (e.g. bug tracking systems), runtime behavior of the software system (e.g. software monitors) and system usage (e.g. end user feedback).

In order to characterize the information to be managed by the intended dashboard, we devised the use of ontologies. The backbone ontology of the intended dashboard is the SDM ontology that can be generalized to other strategic decision-making processes. In addition, we have extended the ontology with two additional packages (see Fig. 1): Quality Assessment (QA) and Rapid Software Development Process (RSDP) to cover the particular domain of the Q-Rapids project that is supporting decision making related to quality requirements in RSD processes.

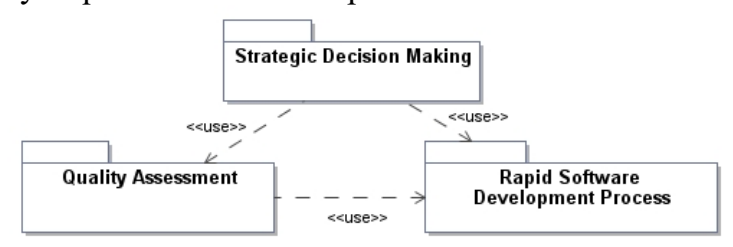

Fig. 1. UML Package Diagram for Strategic Decision Making of Quality in RSD

\footnotetext{
${ }^{6} \mathrm{http}: / /$ www.pmsolutions.com/audio/PM_Performance_and_Value_List_of_Measures.pdf
} 
The conceptualization of the ontologies has followed an iterative and incremental process based on the Methontology conceptualization phase [10]. The proposed ontologies have been empirically-grounded on the basis of the study of four Q-Rapids industrial partners from different European regions and sizes. Q-Rapids industrial partners provide use cases to collect empirical data needed to solidify the objectives of the project and to serve as basis to implement a validation plan. To gather this data, we conducted semi-structured interviews at the industrial partner's premises, in situ observations and accessed to some of their repositories and tools to analyze the data that could be exploited. The main activities performed to define the ontologies were:

- Activity 1: Definition of the ontology structure: Identification of the ontology packages to group concepts with related semantics and to provide a namespace for the grouped elements. We decided to create three different packages (see Fig. 1 ) in order to address and link three relevant problems.

- Activity 2: Extraction of terms relevant for the ontology: Identification and definition of terms including concepts, verbs, instances and properties related to the process of SDM, QA, and RSDP respectively. These terms were discovered and confirmed from the industrial partners' assessment.

- Activity 3: Concept characteristics: We defined the following characteristics for each concept: its attributes, associations with other concepts, generalizations in which the concept is involved and constraints, if any.

We focus on elaborating the SDM ontology and showing its particularization to the QA and RSDP for supporting the objective of Q-Rapids. Some works propose using UML for ontology definition and development [11]. We use UML packages to represent ontology structure and UML class diagrams for defining classes, attributes and the relationships between them.

\section{$4 \quad$ Strategic Decision-Making Ontology}

\subsection{Definition of the Ontology Structure}

The purpose of the SDM ontology is to provide a common underlying language integrating the concepts to manage decisions and to handle strategic indicators and, consequently, it could be used as a basis for the construction of tools supporting strategic decision making. The SDM ontology is structured into two packages: Strategic Indicator and Decision. The former package groups all the concepts related to the strategic indicator concept whereas the latter package groups the concepts related to the decision concept. The <<use>> dependency between both packages defines that the Decision package can access concepts defined in the Strategic Indicator package. Fig. 2 shows the SDM structure as a UML package diagram.

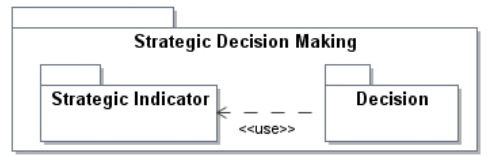

Fig. 2. SDM structure as an UML package 


\subsection{Extraction of Terms Relevant for the Ontology}

Table 1 and Table 2 show the relevant concepts for the SDM ontology, their definition and examples. We extracted those concepts from the following sources:

Table 1. Definition of terms for the Strategic Indicator package of the SDM ontology

\begin{tabular}{|l|l|l|}
\hline \multicolumn{1}{|c|}{ Concept } & \multicolumn{1}{|c|}{ Definition } & \multicolumn{1}{|c|}{ Examples } \\
\hline $\begin{array}{l}\text { Strategic } \\
\text { Indicator }\end{array}$ & $\begin{array}{l}\text { An aspect that a company considers relevant for } \\
\text { the decision-making process }\end{array}$ & $\begin{array}{l}\text { Customer satisfaction, product } \\
\text { quality, blocking }\end{array}$ \\
\hline Entity & $\begin{array}{l}\text { Constituent part of a product and its environment } \\
\text { for which a strategic indicator could be defined }\end{array}$ & Software product, feature \\
\hline Factor & $\begin{array}{l}\text { Property of an entity (or part of it) that is related } \\
\text { to the product's quality }\end{array}$ & Maintainability, reliability \\
\hline KPI & $\begin{array}{l}\text { Metric that measures the degree of achievement of } \\
\text { a strategic indicator }\end{array}$ & $\begin{array}{l}\text { Percentage of user stories } \\
\text { delivered as planned }\end{array}$ \\
\hline $\begin{array}{l}\text { KPI } \\
\text { Evaluation }\end{array}$ & Measurement of a KPI at a certain point of time & $\begin{array}{l}\text { 40\% user stories delivered on } \\
\text { time at the end of iteration 3. }\end{array}$ \\
\hline Role & $\begin{array}{l}\text { Position or purpose that someone has in an organ- } \\
\text { ization }\end{array}$ & $\begin{array}{l}\text { Product manager, software } \\
\text { developer }\end{array}$ \\
\hline
\end{tabular}

Table 2. Definition of terms for the Decision package of the SDM ontology

\begin{tabular}{|c|c|c|}
\hline Concept & Definition & Examples \\
\hline Decision & Determination arrived at after consideration & Hiring another developer \\
\hline $\begin{array}{l}\text { Decision } \\
\text { Maker }\end{array}$ & $\begin{array}{l}\text { A person who makes decisions about a specific } \\
\text { factor }\end{array}$ & Project manager \\
\hline $\begin{array}{l}\text { Decision } \\
\text { Rule }\end{array}$ & $\begin{array}{l}\text { Rule encoding preferences of decision makers } \\
\text { (i.e., several decision alternatives or conflicts) }\end{array}$ & $\begin{array}{l}\text { When a conflict arises, quality } \\
\text { levels will be prioritized }\end{array}$ \\
\hline Constraint & Condition or restriction that affects to a decision & $\begin{array}{l}\text { Developers cannot work in } 2 \\
\text { activities the same day }\end{array}$ \\
\hline $\begin{array}{l}\text { External } \\
\text { Constraint }\end{array}$ & $\begin{array}{l}\text { Constraint representing conditions that are out of } \\
\text { the control of decision makers }\end{array}$ & Project budget \\
\hline $\begin{array}{l}\text { Internal } \\
\text { Constraint }\end{array}$ & $\begin{array}{l}\text { Constraint that encodes conditions that may even- } \\
\text { tually influence decision making }\end{array}$ & $\begin{array}{l}\text { Developers cannot work in } 2 \\
\text { activities the same day }\end{array}$ \\
\hline Action & Something done or performed & $\begin{array}{l}\text { Include a quality requirement } \\
\text { into the backlog }\end{array}$ \\
\hline
\end{tabular}

- The Q-Rapids description of action (the document containing the details of how the Q-Rapids project will be carried out). We reviewed this document to find the terms representing relevant concepts in the strategic decision making. For instance, one of the objectives of the Q-Rapids project is to provide quality-related strategic indicators to support decision makers in managing the development process from a quality-aware perspective. We extracted relevant concepts as Strategic Indicator and Decision Maker from this objective.

- The partners' analysis. As mentioned above, we elaborated and generalized the terms and concept characteristics of the ontologies from the Q-Rapids industrial partners. From the answers to the semi-structured interviews provided by QRapids industrial partners, we confirmed and discovered relevant concepts. For example, one respondent declared "I am also a managing director, which means that I have a role in the upper level decision part of the company". We extracted from this answer relevant concepts as Role and Decision. 
- Literature review. We reviewed the literature for identifying the concepts of strategic decision making relevant for decision makers. For example, in BSC [1], it is proposed to define KPIs to measure strategic indicators and actions that organizations should take to improve the values of their KPIs. We extracted from this reference relevant concepts as KPI and Action.

Other concepts were identified as the ontology construction process was progressing and were generalized to cover different scenarios from those of Q-Rapids.

\subsection{Concept Characteristics}

This section presents the UML class diagrams for both packages of the SDM ontology. Each class diagram represents the concepts, their attributes, associations with other concepts, generalizations in which the concept is involved, and constraints. All this information was extracted from the same sources detailed in the previous section.

Fig. 3 shows the concepts related to the Strategic Indicator concept. A strategic indicator has a name (e.g. customer satisfaction), an optional description and may refine other strategic indicators forming a graph (e.g. customer satisfaction may be refined as time-to-market, product value and product quality). Strategic indicators are defined for an Entity by some Roles of the company (e.g. customer satisfaction may be defined for a specific software product by the product director) and followed by some Roles (e.g. customer satisfaction may be followed by sales employees). Moreover, a strategic indicator may be measured by a KPI (e.g. time-to market may be measured as the time it takes from defining a product to its delivery) and it is related to one or more factors (e.g. customer satisfaction may be related to usability Fac tor). Factors are properties of entities that may be measured. KPI Evaluations are assessed using metrics and evaluations associated to each strategic indicator factor at different time points for a specific KPI .

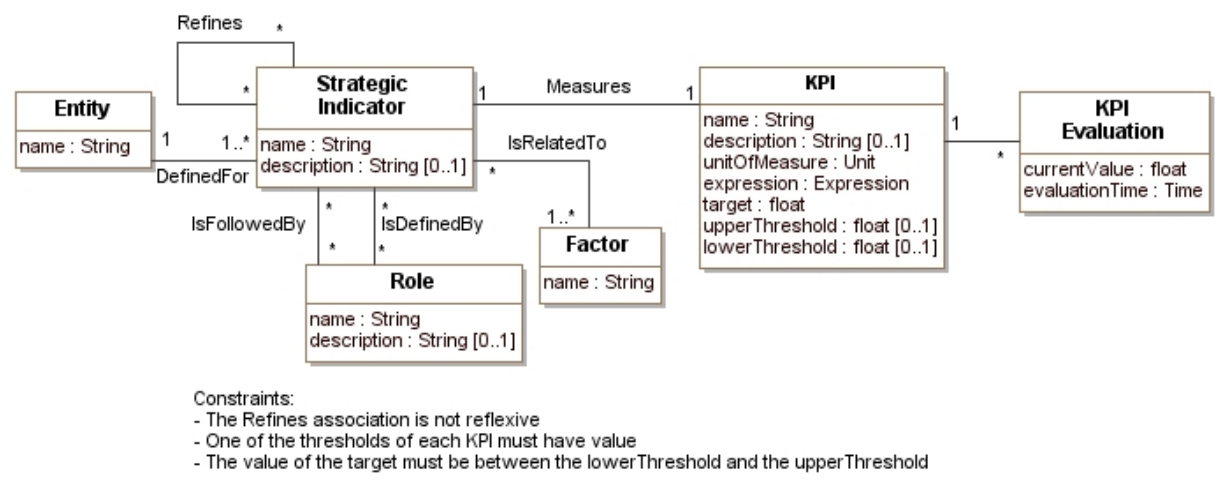

Fig. 3. UML class diagram for the Strategic Indicator package.

Fig. 4 shows the concepts related to Decision. A Decision has a description and a timestamp. Decisions are made by Decision makers (e.g., a project manager decides to hire another developer), may consider Decision rules (e.g., if the percent- 
age of delivered user stories on time is less than $40 \%$, hiring new developers will be prioritized instead of other alternatives) and may be affected by either External or Internal Constraints (e.g., hiring new developers may be constrained by the project budget). A decision may involve one or more Actions (e.g. re-planning the project may involve moving out requirements from the backlog).

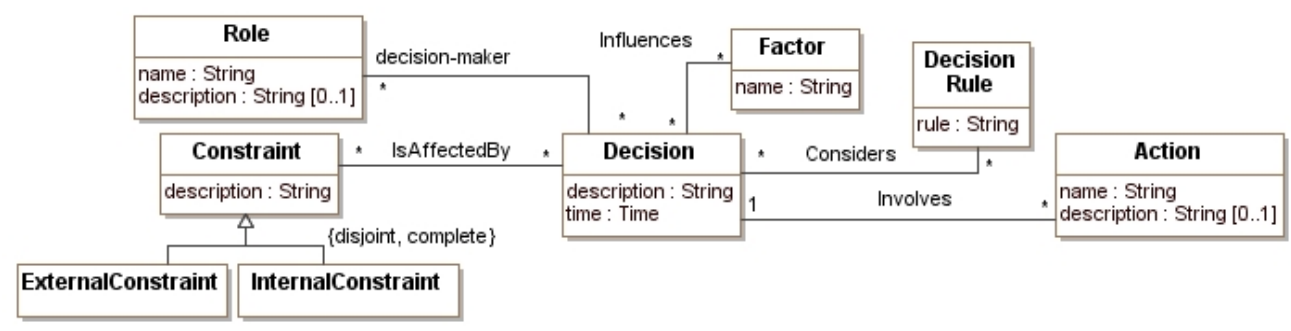

Fig. 4. UML class diagram for the Decision package

The SDM ontology was defined and it is being used in the context of the Q-Rapids project, but it is designed as general-purpose and therefore we argue that it may be used in other contexts, as for instance, to improve the productivity of a product chain.

\section{Extending the SDM Ontology for the Case of Quality in RSD}

The SDM ontology package has been extended with QA and RSDP packages (shown in Fig. 1).

Table 3. Definition of concepts for the QA package

\begin{tabular}{|l|l|l|}
\hline \multicolumn{1}{|c|}{ Concept } & \multicolumn{1}{|c|}{ Definition } & \multicolumn{1}{|c|}{ Examples } \\
\hline Factor & $\begin{array}{l}\text { Property of the software product (or part of it) that } \\
\text { is related to the product's quality }\end{array}$ & $\begin{array}{l}\text { Productivity, Code quali- } \\
\text { ty, Reliability }\end{array}$ \\
\hline Process Factor & Property of the software development process & Productivity \\
\hline Product Factor & Attributes of a software product (or part of it) & Code quality \\
\hline Quality Factor & A property of the software product & Maintainability \\
\hline Data Source & $\begin{array}{l}\text { Contains information to calculate metrics related } \\
\text { to the software product or process }\end{array}$ & $\begin{array}{l}\text { SonarQube, Jenkins, } \\
\text { issue tracking systems }\end{array}$ \\
\hline Metric & $\begin{array}{l}\text { Provides a means to quantify factors that charac- } \\
\text { terize an entity }\end{array}$ & $\begin{array}{l}\text { Lines of code, test cover- } \\
\text { age }\end{array}$ \\
\hline Entity & Constituent part of a software product & Feature, product tests \\
\hline Instrument & $\begin{array}{l}\text { Artifact used to determine the value of a measure, } \\
\text { either using some tool or manually }\end{array}$ & $\begin{array}{l}\text { SQALE plugin of So- } \\
\text { narQube, FindBugs }\end{array}$ \\
\hline Aggregation & $\begin{array}{l}\text { Function used to aggregate values of other } \\
\text { measures }\end{array}$ & Utility functions \\
\hline
\end{tabular}

Specifically, the QA package includes the concepts related to the assessment of the level of software quality during development and runtime. The concepts defined in this package are coming from the Quamoco quality meta-model [12]. Table 3 shows an excerpt of the concepts defined in this package. Factor and Entity redefine the 
same concepts of the SDM ontology. While they are referring to software products in $\mathrm{QA}$, in the SDM ontology they are referring to any kind of products.

The RSDP package includes the concepts related to the development process focusing on the software life cycle integrating quality and functional requirements. The concepts defined in this package are based on the ISO standards for quality management and systems, and software lifecycle processes $[13,14,15]$, as well as proposals for rapid development $[16,17,18]$. Table 4 shows an excerpt of the relevant concepts.

Table 4. Definition of concepts for the RSD package

\begin{tabular}{|c|c|c|}
\hline Concept & Definition & Examples \\
\hline Role & $\begin{array}{l}\text { Position or purpose that someone has in } \\
\text { an organization }\end{array}$ & Product Owner \\
\hline Feature & $\begin{array}{l}\text { Functional or non-functional distinguish- } \\
\text { ing characteristic of a system }\end{array}$ & $\begin{array}{l}\text { Apply standard theme from mail } \\
\text { theme catalogue }\end{array}$ \\
\hline Process & $\begin{array}{l}\text { A set of interrelated or interacting activi- } \\
\text { ties which transforms inputs into outputs }\end{array}$ & $\begin{array}{l}\text { Requirements elicitation, feature } \\
\text { development and testing }\end{array}$ \\
\hline $\begin{array}{l}\text { Quality } \\
\text { Requirement }\end{array}$ & $\begin{array}{l}\text { Specify how well the system performs its } \\
\text { intended functions }\end{array}$ & Performance, maintainability \\
\hline $\begin{array}{l}\text { Rapid } \\
\text { Software } \\
\text { Development }\end{array}$ & $\begin{array}{l}\text { Step from agile software development } \\
\text { that focuses on organizational capability } \\
\text { to develop, release, and learn from soft- } \\
\text { ware in rapid parallel cycles }\end{array}$ & Continuous delivery \\
\hline Release & $\begin{array}{l}\text { Describes an increment into complete } \\
\text { software product valuable to customers }\end{array}$ & $\begin{array}{l}\text { Versions (e.g. Version } 1.0 \text { regis- } \\
\text { tration and login management) }\end{array}$ \\
\hline Sprint & $\begin{array}{l}\text { Short time frame, in which a set of soft- } \\
\text { ware features is developed, leading to a } \\
\text { working product }\end{array}$ & One week sprint \\
\hline $\begin{array}{l}\text { Project } \\
\text { Backlog }\end{array}$ & $\begin{array}{l}\text { The user stories the team has identified } \\
\text { for implementation }\end{array}$ & Collection of user stories \\
\hline User story & $\begin{array}{l}\text { Simple narrative illustrating the user } \\
\text { goals that a software function will satisfy }\end{array}$ & $\begin{array}{l}\text { As a }<\text { tester }>\text {, I want to }<\text { apply } \\
\text { the first prototype standard desk- } \\
\text { top theme }>\text { so that I can }<\text { provide } \\
\text { feedback on the concept }>\end{array}$ \\
\hline
\end{tabular}

Based on the study of each industrial partner of the Q-Rapids project, we gathered substantial data about situations that lead them to make relevant decisions. Among these situations, in this paper, we discuss those situations that negatively influence the progress of software development processes and lead to relevant strategic decisionmaking points in RSD. These situations were referred as "blocking" situations. Reporting these situations in a strategic decision making dashboard may help decision makers to make decisions to correct those situations. In this section, we provide some insights on the use of the SDM ontology extended with the QA and RSDP packages to support the definition of blocking situations.

Blocking was defined as an SDM: :Strategic Indicator. As blocking situations have detected to be relevant mainly at the level of a feature, this strategic indicator was related to the feature as an entity SDM: :Entity:Feature. Based on the information gathered from different participants that played diverse roles in the software development processes, we identified several factors related to the blocking strategic indicator. For reasons of space, we will elaborate just one of these identified factors, namely testing status (i.e., QA: : ProductFactor: Testingstatus). 
We elicited the definition of the testing status factor based on the information provided by some roles. The testing status factor was mentioned among others by test managers as a situation that affects the blocking strategic indicator. For instance, negative integration testing results might block the release of a feature. Therefore, using the RSDP package we instantiated RSD: Role: TestManager.

Testing status was quantified using different metrics, for example: QA: :Metric:TestCoverage and QA: Metric:NumberOfTestsDone. To gather information for such metrics, different modules from continuous integration tools (e.g., Jenkins) or continuous code quality tools (e.g. SonarQube) were used. Therefore, we defined QA: : DataSource: SonarQube as the data source containing the information to calculate the first metric and QA: : DataSource: Jenkins for the second one.

The degree of achievement of the blocking strategic indicator would be defined as an aggregation of values coming from the diverse factors that defines it. Hence, once these aggregations (e.g., AG1, ..., AGn) have been defined, the corresponding SDM:KPI:BlockingKPI can be defined as well. Furthermore, decisions related to blocking can be taken by diverse roles as, for instance, a product manager that given a blocking situation raised by testing status issues on a specific feature, decides DC1: "to postpone the feature to the next release after agreeing that with the corresponding client". Such decision is based on an existing decision rule, DR1: "if the entity causing the testing status issue does not have a high impact on the final product, then it could be postponed to future releases" respecting the internal constraint IC1:"Entity releases must be 100\% agreed with the client". So, SDM: :Role:ProductManager, SDM : : Constraint: InternalConstraint:IC1, SDM: :Decision:DC1, and SDM: : DecisionRule: DR1 are instances of the SDM ontology.

\section{Conclusions}

Organizations make decisions every single day to follow their strategies and to achieve their goals. This paper has presented the SDM ontology to support different strategic decision making processes and extended the ontology to cover the context of managing quality in RSD projects.

As a future work, we are planning to refine the SDM ontology extending it with new concepts to track the reasons of the decisions, to manage the prediction of violations of the strategic indicators and to explore corrective actions in the solution space through what-if-analysis. Moreover, we are going to evaluate the SDM ontology in the context of Q-Rapids industrial partners.

\section{Acknowledgments}

This work is a result of the Q-Rapids project, which has received funding from the European Union's Horizon 2020 research and innovation program under grant agreement $\mathrm{N}^{\circ}$ 732253. We thank to Q-Rapids industrial partners for participating in our empirical studies to develop the presented ontologies. 


\section{References}

1. Kaplan, R.S., Norton, D.P., Dorf, RC., Raitanen. M. The balanced scorecard: translating strategy into action. Vol 4. Harvard Business School press Boston.

2. Object Management Group. Business Motivation Model (BMM) 1.3. (2015). Available at: http://www.omg.org/spec/BMM/1.3, last access April 2017.

3. Barone, D., Mylopoulos, J., Jiang, L., Amyot, D. The Business Intelligence Model: Strategic Modelling (Version 1.0). Available at: ftp://ftp.cs.toronto.edu/csrg-technicalreports/607/BIM-TechReport.pdf, last access July 2017.

4. Diamantini, C., Potena, D., Storti, E., Zhang, H. An Ontology-Based Data Exploration Tool for Key Performance Indicators. In: On the Move to Meaningful Internet Systems: OTM 2014 Conferences. LNCS, vol 8841. Springer, Berlin, Heidelberg

5. Maté, A., Zoumpatianos, K., Palpanas, T., Trujillo, J.C., Mylopoulos, J, Koci, E. A systematic approach for dynamic targeted monitoring of KPIs. In Proc. of the 24th Annual Int. Conference on Computer Science and Software Engineering, pp. 192-206. IBM Corp.

6. Maté A., Trujillo, J.C., Mylopoulos, J. Specification and derivation of key performance indicators for business analytics: A semantic approach. Data \& Knowledge Engineering, Vol 108, March 2017, pp. 30-49.

7. Object Management Group. Decision Model and Notation (DMN) 1.1. (2016). Available at: http://www.omg.org/spec/DMN/1.1/PDF/, last access April 2017.

8. Guzmán, L., Oriol, M., Rodríguez, P., Franch, X., Jedlitschka, A., Oivo, M. How Can Quality Awareness Support Rapid Software Development? - A Research Preview. REFSQ 2017.

9. V. Basili et al. Aligning Organizations through Measurement - The GQM+Strategies Approach. Springer, 2014.

10. Fernández-López, M.,Gómez-Pérez, A., Juristo, N. METHONTOLOGY: From Ontological Art Towards Ontological Engineering. In: AAAI-97 Spring Symposium Series, 24-26 March 1997, Stanford University, USA.

11. Cranefield, S. Networked Knowledge Representation and Exchange using UML and RDF. Journal of Digital information, Vol. 1, No.8 (2001) http://jodi.ecs.soton.ac.uk.

12. Wagner, S., Lochmann, K., Winter, S., Deissenboeck, F., Juergens, E., Herrmannsdoerfer, M., Heinemann, L., Kläs, M., Tendowicz, A., Heidrich, J., Ploesch, R., Goeb, A., Koerner, C., Schoder, K., Streit, J., Schubert, C. The Quamoco quality meta-model. Technical Report TUM-I1281, Technische Universität München.

13. International Standardization Organization/International Electrotechnical Commission (2005). 9000: 2005. Quality management systems-Fundamentals and vocabulary.

14. International Standardization Organization/International Electrotechnical Commission (2008). 12207: 2008. Systems and software engineering-Software life cycle processes.

15. International Standardization Organization/International Electrotechnical Commission (2012). 26515. Systems and software engineering - Developing user documentation in an agile environment. First edition 2011-12-01; Corrected version 2012-03-15.

16. Mäntylä, M.V., Adams, B., Khomh, F., Engström, E., Petersen, K. On Rapid Releases and Software Testing: A Case Study and a Semi-Systematic Literature Review. Empirical Software Engineering (2015) 20: 1384. doi:10.1007/s10664-014-9338-4.

17. Fitzgerald, B.; Stol, K. J. Continuous software engineering: A roadmap and agenda. Journal of Systems and Software, Vol. 123, pp. 176-189.

18. Leffingwell, D. Agile software requirements: lean requirements practices for teams, programs, and the enterprise. Addison-Wesley Professional, 2011. 